\title{
A Universidade Vista "A Certa Distância”: a estrutura social da USP e sua representação simbólica
}

Maria Caramez Carlotto'

\section{Resumo}

O presente artigo inspira-se na sociologia do campo acadêmico de Pierre Bourdieu e na tradição de análise estrutural da história da Universidade de São Paulo (USP) de autores para, a partir da reconstrução da sua estrutura social, com a oposição entre o polo profissional tradicional e o polo acadêmico-científico, analisar sua representação simbólica solene por excelência, o Brasão d'armas da USP. Para tanto, o artigo mobiliza os dados disponibilizados no Anuário Estatístico da USP e no Questionário Socioeconômico da Fuvest, e realiza uma análise iconográfica do brasão da USP.

Palavras-chave: Universidade de São Paulo. História estrutural. Campo acadêmico. Formação de elites.

\section{Introdução}

Uma das questóes mais essenciais para uma sociologia do campo acadêmico que se desenvolva na fronteira da sociologia política diz respeito à forma pela qual os sistemas de ensino reproduzem e naturalizam hierarquia sociais que constituem o campo do poder, contribuindo para a consagração social de elites dirigentes que, pela passagem pelo espaço escolar, tornam-se legitimadas e socializadas para o exercício do poder. É essa a inspiração geral que orienta a análise de Pierre Bourdieu sobre o sistema de ensino superior francês. Nas suas palavras:

O campo universitário reproduz, na sua estrutura, o campo do poder que, através da sua ação própria de seleção e inculcação, ajuda, por sua vez, a reproduzir estruturalmente. É, na verdade, no e pelo funcionamento [do campo universitário] enquanto espaço de diferença entre posições (e, ao mesmo tempo, entre as disposições de seus ocupantes) que se

I Universidade Federal do $A B C$ (UFABC).E-mail: maria.carlotto@ufabc.edu.br 
realiza, para além de toda intervenção das consciências e das vontades individuais ou coletivas, a reprodução do espaço de posições diferenciais que são constitutivas do campo do poder. Como mostra claramente a análise de correspondência, as diferenças que separam as faculdades e as disciplinas, tal como é possível defini-las através das propriedades dos seus professores, apresentam uma estrutura homóloga àquela do campo do poder no seu conjunto: as faculdades temporalmente dominadas, faculdades de ciências, e, em menor grau, faculdades de letras, se opõem às faculdades socialmente dominantes, sob esse aspecto, praticamente idênticas, [como as] faculdades de direito e de medicina, por todo um conjunto de diferenças econômicas, culturais e sociais, onde se reconhece o essencial do que constitui a oposição, no seio do campo do poder, entre a fração dominante e a fração dominada. (BOURDIEU, 1984, p. 62).

Essa proposição específica sobre a existência de uma homologia entre as estruturas universitárias e as estruturas de poder pressupóe, como fica claro no excerto acima, uma operação analítica que busca reconstruir a estrutura social do campo universitário, expressa nas hierarquias que afastam e aproximam as suas diferentes unidades de ensino e pesquisa segundo o padrão acadêmico e o perfil socioeconômico dos seus membros. É essa operação que Bourdieu $(1984,1989)$ realiza na análise do sistema de ensino superior francês, inspirando todo um conjunto de trabalhos subsequentes sobre as hierarquias estruturantes do sistema de ensino superior pensado a partir do conceito de campo (BOURDIEU; SAINT MARTIN, 1987; DUBET, DURU-BELLAT; VÉRÉTOUT, 2012; EURIAT; THÉLOT, 1995; GALL; SOULIÉ, 2007; GARCIA; POUPEAU, 2003; MERLE, 1996).

O presente artigo - que retoma algumas das análises desenvolvidas na minha tese de doutorado intitulada Universitas semper reformanda? A história da Universidade de São Paulo e o discurso da gestão à luz da estrutura social (CARLOTTO, 2014) - parte dessa inspiração geral para, por meio da análise da estrutura social da Universidade de São Paulo (USP), descrever a tradução de hierarquias sociais em hierarquias acadêmicas, bem como a sua naturalização por meio de mecanismos diversos de simbolização, como os que contribuem para definir o sentido da representaçáo mais solene da universidade: o seu Brasão d'armas, hoje convertido em seu símbolo máximo. Para tanto, este texto se divide em três partes, para além desta introdução. Na primeira intitulada Dominantes e dominados no contexto universitário: a estrutura social da USP, procuro reconstruir parte do esforço 
analítico que me permitiu, em trabalho anterior (CARLOTTO, 2014), sistematizar a estrutura social da USP, construída empiricamente como campo. Na segunda, chamada Hierarquias acadêmicas, hierarquias sociais: o brasão da USP como representação simbólica da sua estrutura social procuro mostrar como a análise das relaçóes objetivas, expressão das estruturas sociais que marcam a universidade, só se completa com a análise dos esquemas de percepçáo, de pensamento e de ação, produto dessas estruturas sociais incorporadas enquanto estruturas cognitivas (BOURDIEU, 1989, p. $7 \mathrm{ss}$ ), que concorrem para a naturalização e, portanto, perpetuação dessa mesma estrutura. Na conclusão, procuro mostrar como o esforço essencial deste artigo remonta a toda uma tradição específica de reconstrução histórica da USP, marcada pelo esforço de olhar a universidade "a certa distância”, objetivando a sua estrutura social, e que pode ser compreendido, ele mesmo, estruturalmente.

\section{Dominantes e dominados no contexto universitário: a estrutura social da USP}

Ao descrever o campo universitário francês, tanto em Homo Academicus (1984) quanto em La noblesse d'état (1989), Pierre Bourdieu reconhece a importância da contraposição entre um polo dominado, formado pelas carreiras científicas e certas formaçóes profissionais como letras, e um polo dominante, constituído pelas profissóes socialmente valorizadas, como direito e medicina, como explicitado na citação que abre este artigo. $\mathrm{O}$ autor reconhece, ainda, que essa oposição acadêmica traduz, nos seus próprios termos, diferenças de ordem social, econômica e cultural que também separam estruturalmente essas faculdades e, principalmente, seus membros no espaço exterior à universidade, que Bourdieu denomina de campo do poder.

Foi essa inspiração geral que me levou a desenhar uma pesquisa que pensava empiricamente a USP - a mais tradicional universidade de pesquisa brasileira - como um campo, ou seja, como um espaço socialmente hierarquizado, cuja estrutura de posiçóes permite compreender as disputas essenciais que marcam a universidade ao longo da sua história. Para reconstruir essa estrutura social, mobilizei duas instâncias principais de produção de dados estatísticos sobre a USP: o seu Anuário Estatístico, que sintetiza 
informaçôes de vários órgãos e sistemas centralizados da universidade; e o Questionário Socioeconômico da Fuvest, que permite conhecer, anualmente, o perfil social, cultural, demográfico e econômico dos ingressantes nas diferentes carreiras da universidade ${ }^{2}$.

A análise dos dados disponibilizados no Anuário Estatístico da USP que sistematiza informaçôes, como ano de fundação; cidade sede; regime de trabalho do corpo docente; número de publicaçóes; participação na gestão universitária; número de vagas na graduação e da pós-graduação; número de vagas no noturno e no matutino; velocidade de crescimento e expansão tomando como unidade de medida as diferentes unidades de ensino e pesquisa da USP - mostra que se fosse preciso descrever a trajetória da Universidade de São Paulo entre 1960 e 2014 em apenas duas palavras, essas certamente seriam expansão e diversificação.

Isso porque, ao longo de todo esse período de mais de 50 anos, a USP não só aumentou significativamente o seu número de cursos, unidades e programas, levando a crescimento homólogo do número de alunos de diferentes níveis e, em menor escala, de docentes e de funcionários ${ }^{3}$, como essa expansão esteve atrelada a um intenso processo de diversificação interna que fez com que, às unidades e aos cursos que tradicionalmente compunham a USP, se somasse, a partir da década de 1970, uma série de novas faculdades e carreiras, alterando a configuração original da universidade mais tradicional do país.

Essa relativa expansão, por meio, sobretudo, da criação de novas vagas, não se traduziu de modo imediato numa democratização da USP. Pelo contrário, considerando os dados do Questionário Socioeconômico da Fuvest, é possível notar que o crescimento do número de vagas e de

2 Na minha tese de doutorado, procuro reconstruir a história dessas duas instâncias de produção e sistematização de dados, mostrando como o seu surgimento e consolidação como espaços centralizados de mensuração e seleção é inseparável da própria centralização do poder na USP que permitiu com que a universidade se afirmasse como instituição para além das suas unidades isoladas (CARLOTTO, 2014).

3 Embora não seja objeto deste artigo, vale frisar que a expansão da USP só foi possivel graças a um esforço de centralização e de implementação de mecanismos modernos de gestão que contribuíram para aumentar produtividade do seu corpo docente e funcional, que permaneceu praticamente estagnado ao longo dos últimos anos, com consequências relevantes sobre os padrões tradicionais de organização do trabalho, sobretudo nas unidades vocacionadas para a produção de conhecimento e produtores de conhecimento (CARLOTTO, 20/4). 
inscritos no vestibular da USP entre 1999 e 2009 foi acompanhado por uma relativa elitização do perfil dos candidatos à universidade ${ }^{4}$, o que tendeu a se traduzir em uma progressiva elitização dos próprios ingressantes da universidade (CARLOTTO, 2014).

Essa relativa elitização dos "novos uspianos" não ocorreu, porém, em todos os cursos da universidade. Como existe uma forte relação entre a procura por um determinado curso e a elitização do seu alunado, dado que os filhos de famílias com maior escolaridade e renda tendem a acumular melhores condiçóes de enfrentar a competição pelas vagas escassas (DUBET; DURU-BELLA; VÉRÉTOUT, 2012, p. 48-49), a variação da concorrência no vestibular da USP entre as diferentes carreiras levou a uma elitização diferencial das distintas unidades da universidade. Isso significa que a expansão da USP, que representou em parte um processo de democratização na medida em que ampliou vagas, implicou, ao mesmo tempo, um aumento da sua desigualdade interna, o que, vale dizer, não é uma especificidade da USP, como demonstram outros estudos, sobretudo internacionais, sobre as consequências da expansão quantitativa do ensino superior nas últimas décadas (EURIAT; THÉLOT, 1995; GALL; SOULIÉ, 2007; GARCIA; POUPEAU, 2003; MERLE, 1996)5

Ao analisar, portanto, os processos de expansão, diversificação e elitização da Universidade de São Paulo nos últimos anos, foi possível constatar que esses movimentos tendenciais gerais, que são determinantes na histórica

4 Se em 1999, 54,2\% dos inscritos no vestibular havia cursado o ensino fundamental em escola particular, em 2009, esse percentual já havia aumentado para 60,8\%. Quanto ao ensino médio, se em 1999, 63,8\% dos inscritos havia estudado no sistema privado, em 2009, esse percentual aumentou para 65,5\%. Ao mesmo tempo, a parcela de alunos que fez o ensino médio no período noturno diminuiu, passando de 16,5\% em 1999 para $11 \%$ em 2009. Os alunos que se inscreveram na Fuvest depois de realizar cursinho passaram de 44,6\% do total de inscritos em 1999 para 52,5\% em 2009. Esses dados se completam pelas informações sobre a escolaridade dos pais dos inscritos na Fuvest. Entre 1999 e 2009, os candidatos ao vestibular da USP que tinham pai com ensino superior passaram de 44,3\% para 45,2\%, sendo que o percentual desses com pós-graduação também aumentou de 5,2\% para 6,6\%. Mas foi na escolaridade das mães dos candidatos que a variação foi mais marcante. Se em 1999 apenas 36,5\% dos inscritos eram filhos de mãe com superior completo, das quais 3,0\% com pós-graduação, em 2009 esse percentual tinha subido para 45,4\%, das quais 4,9\% com pós-graduação (CARLOTTO, 2014, p. 350 ss).

5 Em síntese, esses estudos mostram como a democratização quantitativa - ou seja, a simples ampliação do acesso ao ensino superior - não implica, necessariamente, uma democratização qualitativa do sistema, "[...] que descreve o enfraquecimento da relação entre diploma e origem social." (CARCIA; POUPEAU, 2003, p. 75). 
recente da instituição, não se desenvolveram do mesmo modo nos diferentes cursos, carreiras e unidades da universidade (CARLOTTO, 2014). $\mathrm{Na}$ verdade, foi possível observar padróes claramente distintos de evolução, cuja consolidação permite, hoje, definir as posiçóes marcantes do espaço interno da USP, que separam e aproximam suas diferentes unidades. A seguir, apresento de modo sintético essas diferentes posiçôes, descritas como um "polo profissional tradicional", com seu desdobramento em termos de novas unidades de perfil mais técnico e, portanto, menos elitizado e um "polo acadêmico-científico".

\section{O polo profissional tradicional}

Constituído pelas faculdades da USP que reúnem principalmente os cursos de graduação voltados à formação de profissionais liberais cujo diploma tem um alto valor simbólico, no campo econômico, político e social, essas unidades se caracterizam, sobretudo, pelo caráter essencialmente elitizado do seu alunado. Justamente pelo seu recrutamento social elevado, essas unidades se afirmaram como espaços tradicionais de formação e socialização das elites sociais, políticas e econômicas, sobretudo do estado de Sáo Paulo. O núcleo desse polo é formado pelas faculdades profissionais tradicionais concentradas na capital do estado e fundadas antes de 1934 ou, em menor medida, antes da Reforma Universitária de 1968, que elas próprias ajudaram a configurar (CARLOTTO, 2014). São elas:

- Faculdade de Direito (1827)

- Escola Politécnica (1893)

- Faculdade de Ciências Farmacêuticas (1898)

- Faculdade de Odontologia (1898)

- Faculdade de Medicina (1912)

- Faculdade de Medicina Veterinária e Zootecnia (1911)

- Faculdade de Saúde Pública (1919)

- Faculdade de Economia e Contabilidade (1931)

- Faculdade de Arquitetura e Urbanismo (1948) 
Para além desse "núcleo duro", podem ser incluídas nesse polo as faculdades profissionais sediadas fora da cidade de São Paulo e/ou fundadas ao longo dos anos 1960, mas que, igualmente, voltam-se à formação de profissóes tradicionais, socialmente valorizadas que, por isso, atraem um alunado oriundo de camadas sociais privilegiadas. Sáo elas:

- Escola de Agricultura Luiz de Queiróz (1901)

- Faculdade de Odontologia de Bauru (1948)

- Faculdade de Medicina de Ribeirão Preto (1948)

- Escola de Engenharia de São Carlos (1948)

- Escola de Comunicação e Artes (1966)

- Instituto de Psicologia (1969)

- Faculdade de Ciências Farmacêuticas de Ribeirão Preto (1924/1975)

- Faculdades de Odontologia de Ribeirão Preto (1924/1982)

- Faculdade de Economia, Administração e Contabilidade de Ribeirão Preto (2002)

- Instituto de Relaçóes Internacionais (2002)

- Escola de Engenharia de Lorena (2006)

- Faculdade de Direito de Ribeirão Preto (2007)

- Instituto de Arquitetura e Urbanismo de São Carlos (2010)

Juntas, essas unidades compóem o que eu denomino de polo profissional tradicional da USP. É importante notar que denominar esse polo de "profissional" não implica afirmar que as unidades que o configuram se dediquem exclusivamente à formação profissional. Ao contrário, é amplamente reconhecido que essas unidades possuem uma tradição própria de pesquisa e de formação em pós-graduação. Por outro lado, em relação a outras unidades, especialmente as que compóem o que eu denomino de polo acadêmico-científico, é a importância da formação profissional o que as distingue. Não é por acaso, portanto, que as unidades do polo profissional tradicional são as que possuem o menor percentual de docentes em dedicação exclusiva, segundo dados de 2010, conforme a Tabela 1, a 
seguir, que apresenta as unidades de ensino e pesquisa da USP segundo o percentual de professores em regime de dedicação exclusiva em relação à média da universidade.

O dado sobre o percentual relativo de docentes em dedicação exclusiva às atividades universitárias é um indício muito agudo, primeiro, do grau de autonomia e autorreferência dessas unidades, segundo, poder e influência que essas unidades têm fora da universidade e, além disso, do valor social dos diplomas por ela oferecidos, o que torna a atividade acadêmica em si pouco atrativa.

Tabela I - Unidades de ensino e pesquisa da USP hierarquizadas segundo o percentual de docentes em regime de dedicação exclusiva (2010)

Unidades de ensino e pesquisa

Faculdade de Direito

Faculdade de Medicina

Faculdade de Odontologia

Faculdade de Arquitetura e Urbanismo

Faculdade de Direito de Ribeirão Preto

Faculdade de Economia, Administração e Contabilidade

Instituto de Psicologia

Escola Politécnica

Instituto de Relações Internacionais

Escola de Educação Física e Esportes

Escola de Comunicação e Artes

Universidade de São Paulo (total)

Faculdade de Odontologia de Ribeirão Preto

Faculdade de Odontologia de Bauru

Faculdade de Saúde Pública

Faculdade de Ciências Farmacêuticas

Escola de Artes, Ciências e Humanidades

Faculdade de Economia, Administração e Contabilidade de R.P.

Instituto de Química de São Carlos

Escola de Engenharia de São Carlos
Percentual de docentes em

dedicação exclusiva (2010)

$12,65 \%$

$42,16 \%$

$48,05 \%$

$60,00 \%$

$61,53 \%$

$69,02 \%$

$73,33 \%$

$75,87 \%$

$83,33 \%$

$84,09 \%$

$84,31 \%$

$84,73 \%$

$85,41 \%$

$85,47 \%$

$86,46 \%$

$90,10 \%$

$94,26 \%$

$94,31 \%$

$94,33 \%$

$95,02 \%$ 
Unidades de ensino e pesquisa

Instituto de Ciências Biomédicas

Instituto de Matemática e Estatística

Instituto de Geociências

Faculdade de Ciências Farmacêuticas de Ribeirão Preto

Faculdade de Educação

Faculdade de Medicina de Ribeirão Preto

Instituto de Física de São Carlos

Escola Superior de Agronomia Luiz de Queiróz

Escola de Enfermagem

Faculdade de Filosofia, Ciências e Letras de Ribeirão Preto

Instituto de Física

Faculdade de Filosofia, Letras e Ciências Humanas

Instituto de Ciência Matemática e Computação de São Carlos

Instituto de Astronomia, Geofísica e Ciências Atmosféricas

Escola de Enfermagem de Ribeirão Preto

Faculdade de Medicina Veterinária e Zootecnia

Instituto de Biociências

Escola de Educação Física e Esportes de Ribeirão Preto

Faculdade de Zootecnia Engenharia de Alimentos

Instituto Oceanográfico

Instituto de Química

Escola de Engenharia de Lorena

Instituto de Arquitetura e Urbanismo
Percentual de docentes em

dedicação exclusiva (2010)

$95,10 \%$

$95,16 \%$

$95,23 \%$

$96,11 \%$

$96,23 \%$

$97,03 \%$

$97,36 \%$

$97,48 \%$

$97,59 \%$

$97,79 \%$

$97,93 \%$

$98,14 \%$

$98,50 \%$

$98,63 \%$

$98,95 \%$

$98,99 \%$

$99,09 \%$

$100,00 \%$

$100,00 \%$

$100,00 \%$

$100,00 \%$

$s / d$

$s / d$

Fonte: Elaborada pela autora deste artigo a partir de Anuário Estatístico da USP

É dessa perspectiva relacional, também, que devemos olhar para o fato de que essas unidades que compóem o polo profissional tradicional hegemonizam o poder institucional da universidade, como é possível notar pela tabela a seguir, que sintetiza os reitores da USP, e suas respectivas unidades de origem, eleitos ou nomeados entre 1934 e $2018^{6}$.

6 As exceções na tabela confirmam, de certo modo, a regra, de predomínio das áreas profissionais tradicionais. Assim, o professor José Goldemberg, apesar de ser titular do Instituto de Física da USP, prestou concurso 


\section{Tabela 2 - Reitores da USP entre 1934 e 2022, segundo a unidade de origem}

\begin{tabular}{lcc}
\hline Reitor da USP & Período & Unidade de vinculação \\
\hline Reinaldo Porchat & $1934-1937$ & Faculdade de Direito \\
Lúcio Martins Rodrigues & $1938-1939$ & Escola Politécnica \\
Domingos Rubião Alves Meira & $1939-1941$ & Faculdade de Medicina \\
Jorge Americano & $1941-1946$ & Faculdade de Direito \\
Antônio de Almeida Prado & $1946-1947$ & Faculdade de Medicina \\
Benedito Montenegro & $1947-1947$ & Faculdade de Medicina \\
Lineu Prestes & $1947-1949$ & Faculdade de Odontologia \\
Miguel Reale & $1949-1950$ & Faculdade de Direito \\
Luciano Gualberto & $1950-1951$ & Faculdade de Medicina \\
Ernesto de Morais Leme & $1951-1953$ & Faculdade de Direito \\
José Melo Morais & $1954-1955$ & Escola Superior de Agricultura Luiz de Queiroz \\
Alípio Correia Neto & $1955-1957$ & Faculdade de Medicina \\
Gabriel de Teixeira Carvalho & $1957-1960$ & Faculdade de Medicina Veterinária e Zootecnia \\
Antônio Barros de Ulhôa Cintra & $1960-1963$ & Faculdade de Medicina \\
Luiz Antônio da Gama e Silva & $1963-1969$ & Faculdade de Direito \\
Mário Guimarães Ferri* & $1967-1968$ & Faculdade de Filosofia, Ciências e Letras \\
Hélio Lourenço de Oliveira* & $1968-1969$ & Faculdade de Medicina de Ribeirão Preto \\
Alfredo Buzaid & $1969-1969$ & Faculdade de Direito \\
Miguel Reale & $1969-1973$ & Faculdade de Direito \\
Orlando Marques de Paiva & $1973-1979$ & Faculdade de Medicina Veterinária e Zootecnia \\
Waldir Muniz Oliva & $1978-1982$ & Instituto de Matemática e Estatística \\
Antônio Hélio Guerra Vieira & $1983-1986$ & Escola Politécnica \\
José Goldemberg & $1986-1990$ & Instituto de Física \\
\hline
\end{tabular}

originalmente para a Escola Politécnica, onde lecionou até a reforma universitária de 1969, quando todas as cadeiras de física da universidade foram reunidas em um único instituto. 0 professor Roberto Leal Lobo e Silva, do Instituto de Física de São Carlos, é engenheiro de formação, apesar de ter feito doutorado em física e lecionar na área. O professor Ruy Laurenti, vice-reitor em exercício da USP durante 1993, é formado em medicina pela FMUSP, onde fez também a sua pós-graduação, antes de ingressar na Faculdade de Saúde Pública. O professor Flávio Fava de Moraes, titular do Instituto de Ciências Biomédicas, fez graduação da Faculdade de Odontologia de São Paulo e realizou toda a sua carreira de pesquisa na Faculdade de Medicina, onde exerce, hoje, o cargo de diretor da Fundação Faculdade de Medicina. 


\begin{tabular}{lcc}
\hline Reitor da USP & Período & Unidade de vinculação \\
\hline Roberto Leal Lobo e Silva & $1990-1993$ & Instituto de Física e Química de São Carlos \\
Ruy Laurenti* & $1993-1993$ & Faculdade de Saúde Pública \\
Flávio Fava de Moraes & $1993-1997$ & Instituto de Ciências Biomédicas \\
Jacques Marcovitch & $1997-2001$ & Faculdade de Economia e Administração \\
Adolpho José Melfi & $2001-2005$ & Escola Superior de Agricultura Luiz de Queiroz \\
Suely Vilela Sampaio & $2005-2009$ & Faculdade de Ciências Farmacêuticas de \\
João Grandino Rodas & $2010-2014$ & Ribeirão Preto \\
Marco Antônio Zago & $2014-2018$ & Faculdade de Medicina de Ribeirão Preto \\
Vahan Agopyan & $2018-$ & Escola Politécnica \\
\hline
\end{tabular}

Fonte: Elaborada pela autora deste artigo a partir de Anuário Estatístico da USP

Notas: * Vice-reitores em exercício. ** Data prevista para o fim do mandato.

Analisados em conjunto, esses dois dados mostram que as unidades do polo profissional tradicional - que poderiam também ser chamadas, em razão do perfil do seu alunado e da formação que oferecem, de "escolas de elite" (CARLOTTO, 2014) - concentram não só o poder político da USP como, também, os canais de comunicação mais diretos que a universidade estabelece com outros espaços sociais, particularmente o Estado e o mercado, como é possível depreender a partir dos baixos índices de dedicação exclusiva à docência e à pesquisa verificados entre seus professores, que indicam uma forte inserção social do seu corpo docente, seja em outros espaços profissionais do mercado de trabalho, seja em órgãos de controle econômico, político e social, especialmente no aparelho de Estado. É esse índice de "integração social", que em geral traduz uma "adesão à ordem dominante", que aproxima o polo profissional da USP do que Bourdieu denominou, na sua análise sobre o campo universitário francês, de "poder temporal" concentrado pelo "polo mundano" da universidade (BOURDIEU, 1984, p. 99ss). Ainda segundo o autor, esse polo é marcado por uma distância menor em relação aos poderes e espaços socialmente dominantes e, consequentemente, por um grau de autonomia também menor em relação a eles, sobretudo quando comparado ao outro polo essencial do campo universitário, constituído pelas disciplinas intelectuais e científicas, voltadas à produção de conhecimento e à produção de 
produtores de conhecimento. É nesse sentido que, também na USP, ao polo profissional tradicional contrapóe-se um polo acadêmico-científico.

Mas para descrever corretamente a composição desse polo é preciso reconhecer a existência de unidades de ensino e pesquisa marcadas por uma forte ambiguidade. É o caso, por exemplo, da Faculdade de Educação (1934/1969) que, embora tenha uma vocação profissional dada pela ênfase na formação de professores, pedagogos e administradores escolares, preserva-se próxima do polo acadêmico-científico justamente pela peculiaridade da formação que oferece, de natureza acadêmica e pela construção de um campo forte de pesquisas educacionais. Ou ainda, de algumas áreas da Escola de Comunicação e Artes (1966), que concentra alguns dos cursos mais concorridos da universidade como Propaganda \& Marketing e Jornalismo, mas incorpora também carreiras ligadas ao estudo e à pesquisa cultural e artística, que se diferenciam da vocação profissional da maior parte dos seus cursos. Ou mesmo a Escola de Artes, Ciências e Humanidades, prevista para ser um espaço de expansão da formação profissional de caráter mais técnico que revela, quando vista de perto, uma série de disputas internas pela afirmação de um perfil mais acadêmico, que testemunham a força dos padróes e práticas predominantes nas unidades do polo científico da universidade, nas quais a maioria dos seus professores foi formada (GARCIA; CARLOTTO, 2012, 2013; CARLOTTO; GARCIA, 2017).

$\mathrm{Na}$ verdade, uma análise que se concentrasse na compreensão da organização interna das diferentes unidades da USP certamente encontraria ambiguidades e contraposiçóes homólogas às que marcam a universidade como um todo em todas elas. Nesse sentido, por exemplo, seria possível citar o caso da Faculdade de Medicina de Ribeirão Preto que, embora voltada à formação profissional em medicina, assumiu, desde a sua fundação, um perfil mais científico por causa da intervenção direta da Fundação Rockfeller que financiou a criação da unidade, definindo padróes e práticas diferentes das que caracterizam a Escola de Medicina de Pinheiros (MARINHO, 2001). Esse perfil científico se reflete de modo paradigmático na nomeação do seu curso de medicina, chamado de "ciências médicas". No mesmo sentido, da própria Faculdade de Filosofia, Letras e Ciências Humanas - maior unidade da USP - vive constantemente sob o impacto de tensões entre concepçóes de ensino e pesquisa, ligadas muitas vezes às 
posiçôes sociais e institucionais dos seus portadores, que atingem não só a unidade como um todo, mas praticamente todos os seus cursos, departamentos e áreas (ARANTES, 1994; JACKSON, 2007; KEINEIRT; SILVA, 2010; PULICI, 2008). A constatação da complexidade social e acadêmica da USP não invalida a abordagem estrutural que está sendo proposta, que envolve relacionar e hierarquizar, no âmbito da USP, as unidades de ensino e pesquisa, consideradas como uma totalidade mais ou menos coesa.

Ao contrário, é próprio do método estrutural relacional ser capaz de revelar princípios essenciais de hierarquização social, econômica, política e cultural que marcam, de modo sucessivo, os espaços e subespaços sociais. Em síntese, demonstrar a existência de uma contraposição principal - de natureza econômica, social, política e acadêmica - entre um polo profissional e um polo científico-acadêmico no interior da USP, vista, então, como um espaço social estruturado, náo impede - antes supóe - a constatação de outras polarizaçóes dentro dos subcampos que compóem esse espaço, como o subcampo profissional e o subcampo acadêmico-científico, e mesmo dentro das diferentes unidades de ensino e pesquisa, elas mesmas marcadas por polarizaçóes e disputas importantes.

É nesse sentido, aliás, que Bourdieu, ao analisar o campo universitário francês, e encontrando uma oposição essencial entre o valor social e econômico dos diplomas superiores e o perfil socioeconômico dos estudantes que ingressam nas diferentes carreiras, conclui que "[...] essa oposição cardinal é reencontrada no interior de cada um dos subespaços do campo universitário que correspondem aos grandes setores do campo do poder." (BOURDIEU, 1989, p. 205).

É justamente reconhecendo uma hierarquização fundamental no interior do subcampo profissional, que separa e diferencia as unidades profissionalizantes da USP, que proponho a existência de um terceiro polo, constituído pelas unidades voltadas, sobretudo, às novas formaçóes profissionais, em geral, de caráter mais especializado, e pelas unidades dedicadas à formação de profissóes consolidadas que assumem, no entanto, um perfil mais técnico. Optei por denominar esse polo de técnico-profissional justamente por reconhecer que, além de serem voltados à formação de profissionais, os cursos assim classificados destacam-se pelo perfil mais especializado da sua formação. Implícito no movimento de reconhecer a existência 
de um terceiro polo na USP, está o pressuposto de que a contraposição entre concepção e execução ou, em outras palavras, entre uma formação voltada ao exercício do controle social e uma voltada à execução técnica de funçóes especializadas (BOURDIEU, 1989; BOLTANSKI, 1982; PICHON, 2008), que fratura o campo profissional, é mais importante dos que as inúmeras diferenças que atingem o interior do campo acadêmico-científico, como as que separam as áreas científicas de humanas, biológicas e exatas, ou as que opóem os cursos laboratoriais e náo laboratoriais ou, mais recentemente, as que diferenciam os cursos disciplinares das formaçóes multi, trans ou interdisciplinares.

\section{O subpolo técnico-profissional}

Como foi dito, o polo técnico-profissional é composto, sobretudo, pelas novas unidades que concentram os cursos profissionalizantes de caráter mais especializado e pelas unidades da USP mais antigas que, no entanto, se voltam para a formação de profissional mais técnica. O perfil socialmente dominado das formaçóes profissionais oferecidas por essas unidades se reflete claramente no perfil do seu alunado, marcadamente mais popular e mais feminino do que o das outras unidades profissionais (CARLOTTO, 2014). No caso da USP, as unidades que compóem o polo profissional dominado ou técnico-profissional são:

- Escola de Enfermagem (1942/1963)

- Escola de Enfermagem de Ribeirão Preto (1951/1964)

- Escola de Educação Física e Esportes (1969)

- Faculdade de Filosofia, Ciências e Letras de Ribeirão Preto (1959/1974)

- Faculdade de Zootecnia e Engenharia de Alimentos (1992)

- Escola de Artes, Ciências e Humanidades (2004)

- Escola de Educação Física e Esportes de Ribeirão Preto (2007)

Dentre essas unidades, as que se formaram depois de 1970 contribuíram decisivamente para dinamizar a expansão da USP por meio da abertura de novos cursos e vagas, ao passo que as unidades formadas antes 
de 1970, embora tenham permanecido praticamente estagnadas do ponto de vista da abertura de cursos e vagas, continuam sendo um dos principais espaços de inclusão social da USP, pelo fato de se abrirem para novos setores sociais, função que compartilham com o polo acadêmico-científico e que as diferencia das profissóes tradicionais. Esse dado é absolutamente relevante para entender porque esse pode ser caracterizado como um subpolo do campo profissional tradicional: foi graças à sua expansão a partir dos anos 1970 que as unidades mais tradicionais puderam manter-se praticamente estagnadas do ponto de vista da abertura de novas vagas o que, somado a um aumento crescente pela procura dos seus cursos, contribuiu para elitizar ainda mais o seu alunado, aumentando, por sua vez, tanto a percepção do seu caráter "diferenciado" e "excelente" da sua formação quanto, consequentemente, o valor social dos seus diplomas.

É importante notar que o agrupamento dessas unidades da USP em razão do perfil especializado ou técnico da formação profissional que elas oferecem certamente será objeto de protestos e estranhamentos, sobretudo por parte daqueles que, no interior dessas unidades específicas, atuam para afirmá-las enquanto espaços de produção de conhecimento e formação geral. No entanto, esse tipo de reação, mais do que sugerir a fraqueza da análise proposta revela, na verdade, a sua força. O caráter fortemente pejorativo que assumem, no interior da USP, designaçóes como "especializado", "profissional médio" e "técnico" revelam, de modo exemplar, a força das hierarquias sociais que estruturam a USP e que se traduzem, portanto, em esquemas categoriais como os que opóem, no âmbito da universidade, a "formação geral" à "formação técnica", os "dirigentes" aos "especialistas", a "concepçãa” à "execução". É justamente a análise da estrutura social da universidade que permite compreender a força e o significado desses esquemas categoriais, que seráo objeto de análise no tema do próximo item. Mas antes, cabe descrever o outro polo da universidade, o polo acadêmico-científico.

\section{O polo acadêmico-científico}

Composto pelas unidades voltadas à formação científica e pedagógica, fundadas, sobretudo, entre a criaçáo da USP em 1934 e a Reforma Universitária de 1968, no geral com sede na cidade de São Paulo, o 
polo acadêmico-científico reúne unidades historicamente mais abertas a setores sociais menos elitizados quando comparados aos que se destinam ao polo profissional tradicional (CARLOTTO, 2014; FERNANDES, 1975, 1984; LIMONGI, 1988, 1989; MICELI, 1989). Paralelamente, esse polo reúne, também, as disciplinas e áreas marcadas por um grau de autonomia universitária relativamente maior, dado não só pela inserção social mais frágil dos seus alunos e docentes como, também, pelo seu compromisso com a construção de condiçóes institucionais para que a atividade científica, expressa no chamado regime disciplinar, possa funcionar em condiçóes de relativa autonomia ${ }^{7}$. No caso da USP, o núcleo do polo acadêmico-científico reúne, em primeiro lugar, as unidades que compunham a antiga Faculdade de Filosofia, Ciências e Letras (FFCL), fundada em 1934 e fragmentada em 1969. São elas:

- Instituto de Física (1934/1969)

- Instituto de Química (1934/1969)

- Instituto de Biociências (1934/1969)

- Instituto de Matemática e Estatística (1934/1969)

- Instituto de Geociências (1934/1969)

- Faculdade de Filosofia, Letras e Ciências Humanas (1934/1969)

- Faculdade de Educação

Além disso, compóem esse polo outras unidades de vocação científica, embora não vinculadas originalmente à antiga FFCL:

- Instituto Oceanográfico (1946/1951)

- Instituto de Astronomia, Geofísica e Ciências Atmosféricas $(1927 / 1946)$

7 Como procurei mostrar em pesquisa anterior (Carlotto, 2013), a história da institucionalização da ciência no país é inseparável da atuação de cientistas brasileiros, especialmente ligados às ciências exatas, sobretudo à física, na constituição de condições para que a ciência possa funcionar com um grau de autonomia mínimo, dado pelo predomínio da avaliação por pares, por canais de comunicação próprios e mecanismos institucionais de autocontrole dos cientistas sobre o desenvolvimento da ciência, ainda que essas instâncias de autogoverno sejam essencialmente hierarquizadas. 
- Instituto de Ciências Biomédicas (1949/1969)

- Instituto de Ciências Matemáticas e Computação (1971)

- Instituto de Física de São Carlos (1971/1994)

- Instituto de Química de São Carlos (1971/1994)

Essas unidades, como se viu, caracterizam-se por um alto percentual dos seus docentes em dedicação exclusiva ao ensino e à pesquisa bem como por uma importante exclusão dos seus professores das posiçôes de poder no interior da universidade. Por outro lado, os seus docentes participaram de modo ativo do processo de institucionalização da ciência no país (CARLOTTO, 2013; SCHWARTZMAN, 1979), mostrando sua vocaçáo para a garantia de condiçôes mínimas de estabilidade e autonomia exigidas pela atividade acadêmico-científica.

O pressuposto desta pesquisa é que a análise desses diferentes polos da USP só se completa por um tratamento mais sistematizado sobre como a hierarquia acadêmica traduz uma hierarquia social, pensada - como Bourdieu (1984) sugere- como diferenças sociais entre seus membros. Em outras palavras, importa analisar como a topologia acadêmica construída a partir dos padrôes de evolução e diferenciação das unidades da USP traduz ou revela uma natureza social.

Como dito, a presente análise foi feita com base nos dados disponíveis no Anuário Estatístico da USP e do Questionário Socioeconômico da Fuvest, mas nenhuma dessas duas instâncias permite acessar o perfil socioeconômico do corpo docente da USP, nem mesmo do seu corpo discente de pós-graduação. Por isso, a reconstrução da estrutura social da USP foi realizada, neste artigo e em trabalho anterior (CARLOTTO, 2014), por meio das informaçóes sobre o perfil socioeconômico do corpo discente de graduação, acessado a partir da análise dos dados dos ingressantes na Fuvest, quando necessário e possível, complementadas por informaçóes disponíveis no Anuário Estatístico .

8 Embora essa restrição da análise ao perfil socioeconômico dos estudantes de graduação tenha sido, originalmente, de ordem prática - dado que não existem informações públicas, atuais, sobre o perfil socioeconômico dos professores, funcionários e estudantes de pós-graduação da USP - ela acabou mostrando-se bastante acertada. Isso porque o perfil dos alunos que "escolhem" e são "escolhidos" para ingressar em uma determi- 
Ainda do ponto de vista metodológico, é importante frisar que embora os dados do Questionário Socioeconômico da Fuvest sejam gerados, originalmente, por "carreira”, que é a categoria que a Fundação, como entidade relativamente autônoma ${ }^{9}$, utiliza para diferenciar as opçóes de inscrição no vestibular, do ponto de vista do funcionamento da universidade, as carreiras não correspondem de modo direto às suas unidades de ensino e pesquisa $^{10}$, que constituem a fração essencial do poder universitário, expresso, por exemplo, na composição dos seus órgãos deliberativos máximos, nas formas essenciais de distribuição de recursos, de organização das avaliaçóes internas e de estruturação dos procedimentos de gestão da universidade" . Por isso, tornou-se necessário reagrupar as informaçóes do Questionário socioeconômico por unidades universitárias ${ }^{12}$, tal como apresentado no Anuário Estatístico da universidade.

Para garantir o controle sobre variaçóes ocasionais e apreender possíveis dinâmicas temporais relevantes, trabalhei com os questionários de 2000, 2005, 2010 e 2012, considerando variáveis, como escolaridade do pai, escolaridade da mãe, profissão do pai e profissão da mãe, renda familiar, perfil da escola onde realizou o ensino fundamental e médio, período

nada unidade constitui informação essencial sobre a estrutura social da instituição, porque a composição social desse alunado, mais do que o perfil dos docentes e dos pós-graduandos, relaciona-se diretamente como valor diferencial dos diplomas oferecidos por essas unidades e, portanto, com o recrutamento social específico estabelecido pelo aumento da concorrência pelas suas vagas. Assim, apesar de limitado, trata-se do melhor indicador para reconstruir a estrutura social da USP porque permite acessar, de uma só vez, as hierarquias sociais internas e externas à universidade.

9 A Fundação Universitária para o Vestibular foi criada pela USP, composta de um Conselho Curador, formado por membros nomeados pelo reitor da USP, e uma Diretoria Executiva, formada pelo Conselho. Apesar da relação intrínseca com a reitoria, a Fuvest tem autonomia financeira e de gestão e, como se sabe, é responsável inclusive pela seleção para cursos externos à USP, como para a Academia de Policia do Estado de São Paulo e para a Faculdade de Medicina da Santa Casa de Misericórdia de São Paulo.

10 Por exemplo, a carreira denominada "direito", como visto, reúne atualmente dois cursos distintos, sediados em duas unidades diferentes, a FD e a FDRP. Ou, ainda, o caso da carreira chamada "administração, economia, contabilidade e ciências atuariais" que agrega todos os cursos da FEA, São Paulo, em uma única opção de inscrição, diferenciada por modalidade.

$1 /$ Não por acaso, a unidade é a principal categoria que organiza a publicação de dados do Anuário Estatístico da USP desde a sua criação em 1987.

12 Essa operação foi feita, a pedido da pesquisadora, pela equipe estatística da Fuvest. Aproveito para notar que este trabalho não teria sido possivel sem a autorização da vice-diretora executiva da Fuvest na época. Maria Thereza Fraga Rocco. Igualmente imprescindivel foi o trabalho e a dedicação de Renan de Cerqueira Leite. responsável pelo processamento estatístico dos dados do Questionário Socioeconômico da Fuvest. 
em que realizou o ensino médio, se trabalha ou não, perfil étnico racial e gênero $^{13}$. Em todos esses casos, a operação foi a mesma: hierarquizar todas as unidades da USP a partir do perfil social dos seus ingressantes, discriminando a média da universidade, e separando, portanto, as unidades mais e menos elitizadas. Depois de analisar sistematicamente essa série de dados, foi possível constatar que a despeito de variaçóes conjunturais, havia uma persistência do sistema de relaçóes entre as suas diferentes unidades universitárias, que podíamos interpretar como um "invariante estrutural” (BOURDIEU, 1989, p. 266ss).

Esse sistema de relações, que podemos definir como a estrutura social da USP, opóe, de um lado, as faculdades profissionais tradicionais - concentradas, sobretudo, na cidade de Sáo Paulo, marcadas por recrutamento escolar e social altamente seletivo e fortemente elevado voltando-se, portanto, à formação de profissionais destinados a atuar em posiçóes de poder, portanto, como elite dirigente - e, de outro, as "faculdades e institutos voltados à formação científica e à formação de profissionais de menor prestígio social" - ambas relativamente abertas a setores sociais menos favorecidos, como estudantes de escola pública, filhos de famílias de baixa escolaridade e baixa renda e, em menor medida, afrodescendentes, que são formados para exercer atividades ligadas ao ensino e à pesquisa ou para executar funçóes de natureza técnica e especializada. Essa estrutura social geral, que opóe dominantes e dominados no interior da universidade, é constantemente representada, simbolicamente, no interior da universidade. Neste artigo, concentro-me na análise de uma dessas representaçóes, o brasão da universidade.

\section{Hierarquias acadêmicas, hierarquias sociais: uma análise do brasão da USP como representação simbólica da sua estrutura social}

Em escudo antigo o apóstolo São Paulo, sentado numa cátedra guarnecida de ouro encostada a um muro ameiado, acompanhado à destra pelo escudo do Estado de São Paulo e à sinistra pelo da Capital, ambos com seus timbres. O apóstolo de encarnação, vestido de

13 Para uma análise detalhada desses dados, ver: Carlotto, (20/4). 
vermelho e com manto azul, empunha com a destra uma espada em riste e mantém com a sinistra um livro. A cátedra é firmada sobre dois degraus e estes sobre o chão em ponta. Tudo de sua cor. O timbre, uma esfera armilar sainte de ouro. [Abaixo] um listão vermeIho com a divisa "Scientiae Vinces" em letras de prata. São Paulo, dezembro de 1934. Explicação do brasão d'armas da Universidade de São Paulo por José Wasth Rodrigues (Campos, 1954).

A ideia de que a Universidade de São Paulo deva ter um brasão d'armas tem, em si, algo de excêntrico. Uma instituição fundada em pleno século XX, expressão de um anseio modernizador, recorrendo a um símbolo medieval como forma de forjar uma tradição milenar soa, no mínimo, deslocado. De início, a tentação é remeter tal iniciativa à extravagância das nossas "[...] elites agrárias sedentas de títulos que as aproximassem das antigas aristocracias europeias." (SCHWARCZ, 1993, p. 110). No caso do brasão d'armas da USP, entretanto, esconde-se algo mais complexo.

Prova disso é que o significado e a função do brasão d'armas da USP têm sido constantemente atualizados na vida cotidiana da instituição. Tanto é que, ainda hoje, ele é mobilizado como timbre oficial da universidade, acompanhando grande parte dos seus documentos, particularmente os históricos escolares, os comprovantes de matrículas e outros registros acadêmicos de uso cotidiano dos alunos de graduação e pós-graduação. Mais recentemente, ele passou a ilustrar a página inicial do webmail institucional da USP e o site oficial da universidade, deslocando a importância do "logo" da universidade, consolidado nos anos 1990. Além disso, a partir de 2010 passou a constar, acompanhado da sua explicação oficial, na primeira página do anuário estatístico, publicação que divulga os números da USP para dentro e, sobretudo, para fora da universidade. Mas o mais surpreendente e inusitado, a imagem do brasão d'armas também foi espalhada, nos últimos anos, por diversos locais de passagem como os restaurantes universitários reformados, as bibliotecas de diferentes institutos, em entradas e saídas de prédios da universidade. 


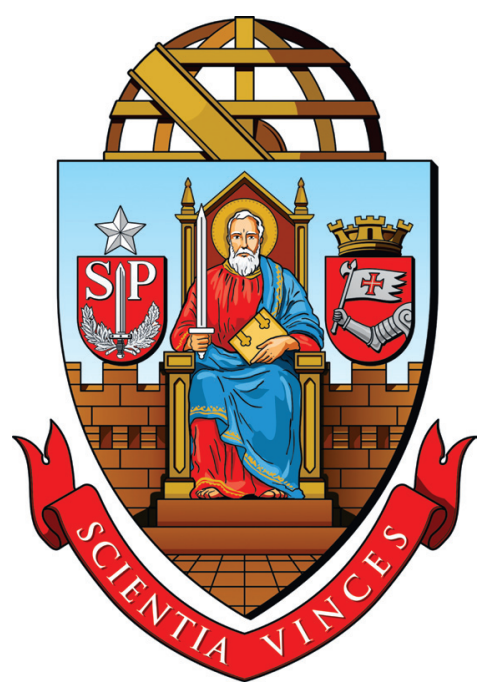

Figura I - Brasão d'armas da USP

Fonte: Universidade de São Paulo

A tendência geral é que em todos esses casos, o brasão seja visto como uma simples imagem, desprovida de qualquer significado mais profundo. No, entanto, o brasão da USP também esconde, nos seus traços mais insignificantes e insólitos, "[...] as grandes linhas de uma estrutura social." que só se mostra, no entanto, "[...] se ficarmos a certa distância." (SCHWARZ, 2000, p. 18) 14. A estrutura social da USP, revelada nas suas linhas gerais no item anterior, ganha representação simbólica em vários momentos da vida universitária, muitos dos quais procurei analisar na minha tese de doutorado (CARLOTTO, 2014). No entanto, o brasão da universidade, por ser a representação solene da autoimagem da universidade, merece atenção especial.

14 Segundo Roberto Schwarz (2000, p. 18), na citação que inspira o título deste artigo, "[...] no romance machadiano praticamente não há frase que não tenha segunda intenção ou propósito espirituoso. A prosa é detalhista ao extremo, sempre à cata de efeitos imediatos, o que amarra a leitura ao pormenor e dificulta a imaginação do panorama. Em consequência, e por causa também da campanha do narrador para chamar atenção sobre si mesmo, a composição do conjunto pouco aparece. Entretanto, ela existe, e, se ficarmos a certa distância, deixa entrever as grandes linhas de uma estrutura social". 
Ao tentar entender o funcionamento social da crença, Pierre Bourdieu (1980) não hesita em afirmar que todas as ordens sociais tiram partido do uso social dos corpos. Essa tendência geral de mobilização de disposiçóes corporais emerge com força, sobretudo, nos momentos em que os grupos buscam "dar uma representação solene" de si mesmos, na "[...] intenção sem dúvida mais obscura de ordenar os pensamentos e de sugerir os sentimentos através de uma ordenação rigorosa das práticas e da disposição regrada dos corpos." (BOURDIEU, 1980, p.116). É o caso, por exemplo, das festas oficiais, das celebraçóes, dos cerimoniais e dos ritos que mobilizam diretamente os corpos individuais, assim como das imagens simbólicas que inscrevem significados sociais na forma de figuração do corpo. Através dessas representaçôes solenes, os valores sociais são incorporados "pela transubstanciaçáo operada na persuasão clandestina de uma pedagogia implícita, capaz de inculcar toda uma cosmologia, uma ética, uma metafísica e uma política” em oposiçóes aparentemente insignificantes, como entre alto e baixo, superior e inferior, direita e esquerda (BOURDIEU, 1980, p. 117). É justamente essa incorporação de sistemas de classificação que constitui o senso prático como uma capacidade de percepçáo e localização quase automática - portanto, impensada - no espaço social.

É nesse sentido que o brasão da USP, representação solene por excelência, coloca o apóstolo Paulo em sua imagem clássica, mas que assume novo significado. Sentado em uma cátedra de ouro, São Paulo empunha na mão direita uma espada em riste, símbolo explícito do poder temporal, ligado, no caso da USP, às faculdades profissionais. Esse significado só se revela plenamente quando lembramos que, ao mesmo tempo, ele segura com a mão esquerda um livro, representando a aspiração intelectual, cuja expressão máxima são as unidades marcadas pelo predomínio da atividade científica, pedagógica e artística. A hierarquia entre um polo e outro é explícita e reforçada pelo paralelismo com os escudos do governo estadual, postado à direita, e da cidade de São Paulo, unidade administrativa indubitavelmente inferior, situado à esquerda. Além disso, a espada levantada, indicando uma açáo iminente, revela a relação de subjugação entre esses dois polos, como de fato é observado quando se considera seu acesso desigual às estruturas internas de poder da universidade. E mesmo que a presença do livro possa representar a intenção de guiar a ação da espada pelo conhecimento 
- sentido reforçado pelo lema Scientiae Vinces, subscrito ao brasão -, é inegável que a imagem prioriza a representação do apóstolo como um "homem de ação", que se vale do conhecimento como instrumento, a serviço do exercício do poder, simbolicamente identificado à espada.

Essa representação que valoriza a USP como espaço de formação de "homens de ação" é de todo afinada à historiografia oficial da USP, não por acaso, uma das principais responsáveis pela consagração do brasão como símbolo institucional ${ }^{15}$. De fato, a historiografia sobre a Universidade de São Paulo se divide em duas grandes tradiçôes (CARLOTTO, 2014, 2017): de um lado, uma história oficial e laudatória, expressa em publicaçôes oficiais e, em geral, de luxo, que enaltecem, sobretudo por meio do relato pessoal como fonte, a longa e bem-sucedida trajetória do projeto uspiano, que remonta às escolas profissionais e isoladas de São Paulo, fundadas no século XIX, e à açáo constante dos seus quadros dirigentes, representados como heróis (AMERICANO, 1947; CAMPOS, 1954; MARCOVITCH, 2011; MENDES, 1977; MOTOYAMA, 2006; OBA, 2006; OLIVEIRA, 1995; REALE, 1986A, 1986B, 1987, 1994; RODAS; MOTOYAMA, 2011). De outro, lado os estudos críticos de filosofia e história da educação que, sem alcançarem qualquer forma de publicação formal, denunciam ao contrário a falência do projeto original da USP, que teria nos departamentos de filosofia e ciências básicas, fundados em 1934, o seu núcleo articulador, desconsiderado pela ação isolacionista das unidades pré-universitárias, de formação profissional tradicional e, portanto, bacharelescas e pré-científicas (ANTUNHA, 1971; BONTEMPI JR., 2003, 2007, 2011; FÉTIZON, 1986).

Essas diferentes "visóes de passado" correspondem a diferentes posições sociais dentro da universidade. De um lado, justamente, o polo profissional tradicional, que controlando o poder interno da universidade, controla as instâncias de produção da sua história oficial, que aparece assim como uma "história dos vencedores". De outro, o polo acadêmico-científico formado

15 O livro de Ernesto de Souza Campos (1954), primeira grande expressão da historiografia oficial da USP, traz o brasão da USP e a sua descrição logo na abertura. Rosana Oba (2006), funcionária da reitoria e autora do liuro Universidade de São Paulo seus reitores e seus símbolos - um pouco da história, também se dedica à análise do brasão d'armas da USP. 
originalmente pela Faculdade de Filosofia, Ciências e Letras que, representando os valores intelectuais por excelência, carecem de poder interno para viabilizá-los plenamente, restando a tarefa de escrever uma história crítica, indubitavelmente "dos vencidos"

\section{Conclusão: a USP vista “a certa distância”}

Do ponto de vista da análise sociológica, interessa notar que, por trás desses modelos de interpretação histórica opostos, esconde-se todo um conjunto de esquemas categoriais que, na sua contraposição, mimetizam a polarização essencial do espaço universitário uspiano: cursos profissionais - cursos científicos; utilidade - desinteresse; local - universal; comprometimento - autonomia; expertise - conhecimento; prática - teoria; tecnologia - ciência; técnica - filosofia; isolamento - integraçáo. São algumas das oposiçóes cognitivas, ao mesmo tempo lógicas e axiológicas, que revelam a força dos dois extremos principais que estruturam a USP. É a estrutura da Universidade com a sua ordem cristalizada de valores corporificada na imagem do "apóstolo de encarnação" (CAMPOS, $1954)^{16}$. Uma estrutura ao mesmo tempo acadêmica e social que hierarquiza o espaço de tomadas de posição na universidade e que só se revela se olharmos a USP "a certa distância”.

A noção de distância, que orientou a proposta deste artigo, opera quase como uma metáfora do processo de objetivação da estrutura social que busca revelar o sentido mais profundo dessas representaçóes simbólicas do mundo social. É esse movimento de objetivação que caracteriza, em linhas gerais, a terceira e última linha de reconstrução histórica da USP, à qual se filia este artigo: a história estrutural.

16 A oposição encarnada pelo brasão d'armas da USP repõe uma polaridade que não é nova, tampouco subsiste só na USP. Immanuel Kant, ao descrever O conflito das faculdades, no final do século XVIII, localiza a "classe das faculdades superiores", comprometidas com os interesses do governo, logo, com o exercício do poder, à direita do parlamento da ciência, ao passo que a "faculdade inferior", "[...] aquela que unicamente tem de velar pelo interesse da ciência.", permanece à esquerda desse parlamento (KANT, 1993, p. 40). Nesse caso, as faculdades localizadas à direita eram representadas pelo direito, a medicina e a teologia, as três principais formações profissionais da época, ao passo que a faculdade à esquerda era essencialmente a Faculdade de Filosofia, expressão do polo científico em momento em que as ciências não se encontravam, ainda, institucionalizadas em diferentes disciplinas. Mas por trás dessas variações históricas, o exemplo de Kant, não por acaso mobilizado também por Bourdieu (1984), permite pensar nos invariantes estruturais da história universitária. 
Formulada no âmbito das ciências sociais, originalmente agrupadas na Faculdade de Filosofia, Ciências e Letras e hoje concentradas na Faculdade de Filosofia, Letras e Ciências Humanas da USP, essa linha de trabalhos se caracteriza, sobretudo, pelo pressuposto de que as concepçóes de universidade que marcam as disputas internas à USP se explicam, em grande medida, pela posição social dos diferentes setores engajados nesses conflitos. São exemplos dessa linha de reconstruçáo histórica os trabalhos de Florestan Fernandes (1975, 1984), Sergio Miceli (1989), Fernando Limongi (1988, 1989), Elza Nadai (1981) e, em certo sentido, Irene Cardoso (1982).

A despeito das suas diferenças internas, esses estudos compartilham o mesmo pressuposto de que a história da USP é marcada por uma longa disputa pela definição de modelos institucionais e de padróes de trabalho intelectual aos quais correspondem concepçóes de mundo inerentes às posiçóes sociais ocupadas pelos agentes e grupos que protagonizam essas disputas. A tese essencial dessa abordagem histórico-estrutural é que a história da USP é marcada por um conflito essencial entre um polo formado pelas escolas profissionais tradicionais, às quais corresponde um padrão de recrutamento social elevado, e um polo formado pelos cursos de vocação intelectual e científica, acessado por setores relativamente menos privilegiados, particularmente das classes médias urbanas que buscam, na universidade, um caminho para a sua profissionalização (FERNANDES, 1975, 1984; LIMONGI, 1989; MICELI, 1989; NADAI, 1981) ${ }^{17}$.

Essa tese geral tende a ser sustentada por uma pesquisa empírica extensa e sistemática, de perfil mais estatístico (FERNANDES, 1975, 1984; LIMONGI, 1989; MICELI, 1989) ou documental (CARDOSO, 1982; NADAI, 1981). Em ambos os casos, a investigação segue um enquadramento teórico bem definido e uma preocupação metodológica correlata, o que testemunha a permanência do padrão de trabalho intelectual que Miceli (1989) associa às ciências sociais paulistas entre 1930 e 1964 e que Antonio Candido diz permitir "certo afastamento" que garante um "[...] olhar sem paixão e quem sabe 'sem piedade” (CANDIDO, 2001, p. 72-73).

17 Neste artigo eu procurei mostrar como essa estrutura essencial é atualizada, mais recentemente, pela expansão de vagas protagonizada pelo subpolo técnico-profissional que, ao permitir com que as profissões tradicionais permaneçam relativamente indiferentes à demanda por democratização e expansão, reforçam a estrutura social da USP. 
Dentre as ciências sociais, foi a sociologia que levou essa busca por "distância” mais longe ${ }^{18}$. Não é coincidência, portanto, que seja também em termos de "distância” que Pierre Bourdieu (1980, p. 29) define “[...] o privilégio epistemológico do observador" Privilégio, esse, que permite romper com a apreensão imediata do mundo, inscrita no senso comum hegemônico em diferentes espaços, para construir um conhecimento objetivo do universo social capaz de identificar as diferentes posiçóes que estruturam a sociedade e a sua percepção, inclusive, para não dizer, sobretudo, a própria posição de observador “distanciado". É nesse sentido que a objetividade depende não somente do afastamento metodológico em relação ao objeto, mas, principalmente, do movimento reflexivo de análise das condiçôes sociais que permitem tal "distanciamento", fonte da possibilidade mesma de objetivação do mundo $^{19}$.

$\mathrm{Na}$ sua análise sobre Os condicionantes do desenvolvimento das ciências sociais no Brasil entre 1930 e 1964, Sergio Miceli (1989, p. 93) apresentou uma ampla explicação de por que, na tradição sociológica paulista, predominou justamente uma abordagem voltada à análise das "condiçóes estruturais". Segundo o autor, a consolidação das ciências sociais brasileiras dependeu de dois padróes diferenciados de institucionalização associados a demandas sociais igualmente distintas: um, marcado "[...] pelo impulso da organização universitária.", atendeu às demandas de grupos sociais emergentes; outro, ligado à "[...] concessão de recursos governamentais para a montagem de centros de debate e investigaçáo.", respondeu aos interesses de setores políticos dirigentes (MICELI, 1989, p. 72).

18 Essa "distância" deve ser pensada em termos metodológicos, e não políticos. Ela representa, portanto, um esforço de distanciamento do objeto pela mobilização de métodos e instrumentos de análise que possibilitem romper com as percepções e visões determinadas diretamente pela experiência nesse mundo, não um distanciamento prático, como possivel sinônimo de "neutralidade", das disputas materiais e simbólicas que se travam no interior da politica universitária.

19 Dirá Bourdieu (1980, p. 29-30): "Se contra o intuicionismo que nega ficticiamente a distância entre o observador e o observado, eu me mantinha ao lado do objetivismo que buscava compreender a lógica das práticas, ao preço de uma ruptura metódica com a experiência originária, eu não deixei de pensar que era preciso também compreender a lógica específica dessa forma de 'compreensão sem experiência' que possibilita o conhecimento dos princípios da experiência; [assim como não deixei de considerar] que era preciso, ao invés de abolir magicamente a distância por uma falsa participação primitivista, objetivar essa distância objetivante e as condições sociais que a tornam possível, como a exterioridade do observador, as técnicas de objetivação de que dispõe etc.". 
Como o autor demonstra, esses dois perfis de consolidação institucional, que atravessaram quase todo o século XX, diferenciavam o tipo de ciência social desenvolvida nos dois principais centros urbanos da época, São Paulo e Rio de Janeiro, segundo diversos aspectos, mas, especialmente, a partir do espaço social de recrutamento dos seus realizadores, da distância em relação às faculdades profissionais tradicionais e do seu grau de autonomia relativa (MICELI, 1989). O contraste entre um polo e outro é tão grande, que o autor chega a afirmar, de modo extremo, que "[...] o Rio de Janeiro está para a política assim como São Paulo está para a ciência." (MICELI, 1989, p. 89). Mas ao invés de atribuir essa diferença à cultura ou à mentalidade distintas das duas cidades, Miceli incorpora o pressuposto materialista de Bourdieu e a procura na desigualdade "de condiçôes" (BOURDIEU, 1980), mais especificamente, de condiçôes de realização da atividade intelectual.

Nesse sentido, a partir do seu desenvolvimento universitário, as ciências sociais em São Paulo foram marcadas por um padrão de recrutamento distinto do que caracterizava, até então, outros setores do ensino superior, como as faculdades profissionais, consequência da abertura da carreira de cientista social a mulheres e a filhos de imigrantes, incluindo os de origem japonesa, árabe e judia (MICELI, 1989). Esse afastamento em relação às faculdades tradicionais, marcadas por um recrutamento mais seletivo, foi reforçado pelo estabelecimento de "[...] procedimentos, exigências e critérios acadêmicos de avaliação, titulação e promoção.” (MICELI, 1989, p. 81) até então inexistentes nesses outros espaços, sobretudo a partir da influência de professores estrangeiros que contribuíram para a profissionalização do trabalho intelectual. Tudo isso concorreu para consolidar um padrão de pesquisa e trabalho marcado por uma considerável margem de autonomia, em que a escolha de temas e problemas de investigação respondia antes a uma hierarquia científica do que a uma escala de relevância político-social.

O interesse da análise de Miceli, neste artigo, reside na forma sistemática como o autor analisa as condiçóes materiais, intelectuais e institucionais que possibilitaram à ciência social uspiana desenvolver uma abordagem estrutural marcada essencialmente por um "esforço de objetivação", inerente à sua "mentalidade cientificista". É claro que essa perspectiva 
estrutural não assume uma feição única. Entre as tintas funcionalistas que caracterizavam as pesquisas dos anos 1950 à sociologia bourdieusiana que passa a influenciar parte importante dos trabalhos a partir dos anos 1980 existe uma sucessão de críticas internas, rupturas e distanciamentos. Ainda assim, é possível reconhecer - sobretudo em relação às outras tradições de reconstrução histórica - uma linha de continuidade na ênfase dada à identificação e à análise das estruturas sociais, também nomeadas "condicionantes", "determinantes" ou "constrangimentos", que definem os limites e possibilidades da ação social e, com ela, do desenvolvimento institucional.

Essa ênfase se manifesta de modo marcante nas análises histórico-estruturais sobre o ensino superior e, em especial, sobre a própria USP. Essa sociologia histórica, que este trabalho atribuiu inicialmente a Pierre Bourdieu (1984, 1989), encontra, portanto, um desenvolvimento particular no contexto brasileiro, que define uma ordem própria de objetos e problemas. É esse movimento de objetivação que caracteriza, em linhas gerais, o esforço deste artigo: olhar a USP a certa distância, procurando reconstruir sua história estrutural.

\section{Referências}

AMERICANO, J. A Universidade de Sáo Paulo: dados, problemas e planos. São Paulo: Empresa Revista dos Tribunais, 1947.

ANTUNHA, H. Universidade de Sáo Paulo: fundação e reforma. 1971, 252f. Tese (Doutorado em Educação) - Faculdade de Educação, Universidade de São Paulo, São Paulo, 1971.

ARANTES, P. E. Um departamento francês de ultramar. Estudos sobre a formação da cultura filosófica uspiana (uma experiência nos anos 60). São Paulo: Paz e Terra, 1994.

ARUM, R.; GAMORAN, A.; SHAVIT, Y. More inclusion than diversion: expansion, differentiation and markets structures in higher education. In: ARUM, R. et al. Stratification in higher education: a comparative study. Stanford: Stanford University Press, 2007. p. 1-35.

BOLTANSKI, L. Les cadres: la formation d'un groupe social. Paris: Les Éditions de Minuit, 1982. BONTEMPI JR., B. A educação brasileira e a sua periodização: vestígio de uma identidade disciplinar. Revista Brasileira de História da Educaçáo. Maringa, n. 5, p. 43-68, 2003. 
O ensino e a pesquisa em história da educação brasileira na cadeira de filosofia e história da educação, 1933-1962. História da Educaçáo. São Paulo, n. 21, p. 79-105, 2007.

Do Instituto de Educação à Faculdade de Filosofia da Universidade de Sáo Paulo. Cadernos de Pesquisa, São Paulo, v. 41, n. 142, p. 188-207, 2011.

BOURDIEU, P. Le sens pratique. Paris: Les Éditions de Minuit, 1980.

. Homo academicus. Paris: Les Éditions de Minuit, 1984.

Variations et invariants. Éléments pour une histoire structurale du champ des grandes écoles. Actes de la Recherche en Sciences Sociales, Paris, n. 70, p. 3-30, 1987.

La noblesse d'état. Grandes écoles et esprit de corps. Paris: Les Éditions de Minuit, 1989.

BOURDIEU, P.; SAINT MARTIN, M de. Agrégation et ségrégation. Le champ des grandes écoles et le champ du pouvoir. Actes de la Recherche en Sciences Sociales, Paris, n. 69, p. 2-50, 1987.

CAMPOS, E. S. A história da Universidade de São Paulo. São Paulo: Universidade de São Paulo, 1954.

CANDIDO, A. Prefácio. In: MICELI, S. Intelectuais à brasileira. São Paulo: Companhia das Letras, 2001. p. 71-5.

CARDOSO, I. A universidade da comunháo paulista. São Paulo: Cortez, 1982.

CARLOTTO, M. C. Veredas da mudança na ciência brasileira. Discurso, institucionalização e práticas no cenário contemporâneo. São Paulo: Scientiae Studia; Editora 34, 2013.

Universitas semper reformanda? A Universidade de São Paulo e o discurso da gestão à luz da estrutura social. 2014. 570 f. Tese (Doutorado em Sociologia) - Programa de Pós-Graduação em Sociologia. Faculdade de Filosofia. Letras e Ciências Humanas. Universidade de São Paulo, São Paulo, 2014.

CARLOTTO, M. C; GARCIA, S. G. Novos saberes, novas hierarquias. Disputas contemporâneas em torno da profissão acadêmica. Revista Brasileira de Ciências Sociais, São Paulo, v. 33, n. 96, p. 1-19, 2018.

DUBET, F.; DURU-BELLAT, M.; VÉRÉTOUT, A.. As desigualdades escolares antes e depois da escola: organização escolar e influência dos diplomas. Sociologias, Porto Alegre, v. 14, n. 29, p. 22-70, 2012.

EURIAT, M.: THÉLOT, C. Le recrutement social de l'élite scolaire en France. Evólution des inegalités de 1950 à 1990. Revue Française de Sociologie, Paris, n. 36, p. 403-13, 1995. 
FERNANDES, F. Universidade brasileira: reforma ou revolução. São Paulo: Alfa-ômega, 1975. A questão da USP. São Paulo: Brasiliense, 1984.

FÉTIZON, B. Subsídios para o estudo da Universidade de Sáo Paulo. vol. 3. 1986. Tese (Doutorado em Educaçáo) - Faculdade de Educação, Universidade de São Paulo, São Paulo, 1986.

GALL, B.; SOULIE, C. Massification, professionnalisation, réforme du gouvernement des universités et actualisation du conflit des facultés en France. In: Gall, B.; Soulié, C. (Org.). Les ravages de la modernisation universitaire en Europe. Paris: Éditions Syllepse, 2007. p. 173-208.

GARCIA, S.; POUPEAU, F. La mesure de la démocratisation scolaire. Actes de la Recherche en Sciences Sociales, n. 149, p. 74-87, 2003.

GARCIA, S. G; CARLOTTO, M. C. Institutional specificity and organizational change: A case of university social engagement in Brazil. In: PINHEIRO, R. et al. (Ed.). Universities and regional development: a critical assessment of tensions and contradictions. London \& New York: Routledge, Taylor and Francis, 2012. p. 124-140.

- Tensôes e contradiçóes do conceito de organização aplicado à universidade: o caso da criação da USP-Leste. Avaliaçáo, Campinas, v. 18, p. 657-684, 2013

KANT, I. O conflito das faculdades. Lisboa: Ediçōes 70, 1993.

JACKSON, L. C. Geraçôes pioneiras na sociologia paulista, 1934-1969. Tempo Social, São Paulo, v. 19, n. 1, p. 115-30, 2007.

KEINERT, F. C; Silva, D. P. A gênese da ciência política brasileira. Tempo Social, São Paulo, v. 22, n. 1, p. 79-98, 2010.

LIMONGI, F. Educadores e empresários culturais na construção da USP. 1988. 279f. Dissertação (Mestrado em Ciência Política) - Instituto de Filosofia e Ciências Humanas. Universidade Estadual de Campinas, Campinas, 1988.

Mentores e clientelas na Universidade de São Paulo. In: MICELI, S. (Org.). História das ciências sociais no Brasil. vol. 1. São Paulo: Vértice/Editora Revista dos Tribunais/IDESP, 1989. p. 111-86.

MARCOVITCH, J. Universidade viva, diário de um reitor. São Paulo: Mandarim, 2001.

MARINHO, M. G. Norte-americanos no Brasil: uma história da Fundação Rockfeller na Universidade de São Paulo, 1934-1952. Campinas/São Paulo: Editores Associados/Universidade São Francisco, 2001. 
MENDES, J.C. Universidade de São Paulo, súmula da sua história. São Paulo: Secretaria da Cultura, Ciência e Tecnologia; Academia de Ciências do Estado de São Paulo, 1977.

MERLE, P. Les principales transformations sociodémographiques des filières de l'enseignement superieur de 1985 à 1995. Population, (S.l.), n. 6, p. 1181-1210, 1996.

MICELI, S. Condicionantes do desenvolvimento das ciências sociais. In: MICELI, S. (Org.) História das ciências sociais no Brasil. São Paulo: Vértice/Editora Revista dos Tribunais/Idesp, 1989. p. 72-110.

Intelectuais à brasileira. São Paulo: Companhia das Letras, 2001.

MILOT, P. La reconfiguration des universités selon l'OCDE. Economie du savoir et politique de l'innovation. Actes de la Recherche en Sciences Sociales, Paris, n. 148, p. 68-73, 2003.

MOTOYAMA, S. (Org.). USP 70 anos, imagens de uma história vivida. São Paulo, Edusp, 2006.

NADAI, E. Ideologia do progresso e ensino superior Sáo Paulo 1891-1934. 1981. 417 f. Tese (Doutorado em História). Faculdade de Filosofia, Letras e Ciências Humanas, Universidade de São Paulo, São Paulo, 1981.

OBA, R. Universidade de Sáo Paulo seus reitores e seus símbolos. Um pouco da história. São Paulo: Edusp, 2006.

OLIVEIRA, H. L. (Org.). USP 1968-1969: Hélio Lourenço de Oliveira. São Paulo: Edusp, 1995. PICHON, A. Les cadres à l'épreuve. Confiance, méfiance, défiance. Paris: Presses Universitaires de France, 2008.

PULICI, C. Entre sociólogos: versões conflitivas da condição de sociólogo na USP dos anos 19501960. São Paulo: Edusp, 2008.

REALE, M. Recordaçóes da Universidade de São Paulo. Revista da Universidade de Sáo Paulo, São Paulo, v. 3, p. 91-101, 1986a.

Memórias: destinos cruzados. vol. 1. São Paulo: Saraiva, 1986b. Memórias: a balança e a espada. vol. 1. São Paulo: Saraiva, 1987. . Minhas memórias da USP. Estudos Avançados, São Paulo, v. 8, n. 22, p. 25-46, 1994.

RODAS, J. G.; MOTOYAMA, S. História da Universidade de São Paulo. Educação Brasileira: Revista do Conselho de Reitores das Universidades Brasileiras, Brasília, DF, v. 33, n. 66, p. 11-48, 2011. 
SCHWARCZ, L. M. O espetáculo das raças: cientistas, instituiçóes e a questão racial no Brasil, 1870-1930. São Paulo: Companhia das Letras, 1993.

SCHWARZ, R. Um mestre na periferia do capitalismo. São Paulo: Editora 34, 2000.

SCHWARTZMAN, S. Formaçáo da comunidade científica no Brasil. Rio de Janeiro: Editora Nacional/Finep, 1979.

SETTON, M. G. J. A divisão interna do campo universitário: uma tentativa de classificação. Revista Brasileira de Estudos Pedagógicos, Brasília, DF, v. 80, n. 196, p. 451-71, 1999.

\section{The University Seen From "Certain Distance": the social structure of USP and its symbolic representation}

\section{Abstract}

These articles is inspired on the sociology of academic field of Pierre Bourdieu and on the tradition of structural analysis of the history of the USP to, by the reconstruction of its social structure, analyze its most important symbolic representation: the crest. The article shows that the USP social structure is better described by an opposition between its traditional professional pole and its academic-scientific pole. To do so, it mobilizes the data available in the USP Statistical Yearbook and Fuvest Socioeconomic Questionnaire, and performs an iconographic analysis of the USP Coat of Arms.

Keywords: São Paulo University. Structural history. Academic field. Elite education.

Recebido em: 18.08.2017

Aprovado em: 28.02.2018 